\title{
A LINGUISTIC LANDSCAPE ANALYSIS OF PUBLIC SIGNS AFTER TYPHOON HAIYAN
}

\author{
Glenda Doroja-Cadiente* \\ Language and Literature Unit, Leyte Normal University, \\ Paterno St. Downtown, Tacloban City 6500 Leyte, Philippines \\ E-mail: glenda_cadiente@dlsu.edu.ph \\ Paolo Nino Valdez ${ }^{* *}$ \\ Department of English and Applied Linguistics, De La Salle University, \\ 2401 Taft Avenue 0922 Manila, Philippines \\ E-mail: paolo.valdez@dlsu.edu.ph
}

\section{Published online: 15 January 2019}

To cite this article: Doroja-Cadiente, G. and Valdez, P. N. 2019. A linguistic landscape analysis of public signs after Typhoon Haiyan. International Journal of Asia Pacific Studies 15 (1): 33-57, https://doi.org/10.21315/ijaps2019.15.1.2

To link to this article: https://doi.org/10.21315/ijaps2019.15.1.2

\begin{abstract}
Throughout the years, linguistic landscape research has emerged as a formidable approach in examining the role of public signs in social life in different communities. From a wider perspective, the study of public signs shows the influence of multilingualism on the social life of communities as they are tied to cultural, sociopolitical and even economic ideologies. However, the role of these signs that reflect the sentiments of members of a community after a natural disaster remains understudied. In 2013, Typhoon Yolanda (international name "Haiyan") struck the Philippines, resulting in numerous deaths and extensive property damage. This paper examines the competing voices of representation through public signs produced by community members affected by Typhoon Haiyan in 2013. The study initially foregrounds the investigation by situating the current beliefs on multilingualism and the apparent need to explore its role in addressing issues brought about by natural calamities. It then proceeds with examining relevant investigations on linguistic landscapes that may be helpful in the present investigation. Through an analysis of photographs of public signs produced after the tragedy, there appears to be two
\end{abstract}


distinct producers of linguistic landscapes: the locals and stakeholders (businesses and government). The signs from these groups each have different characteristics in terms of materials used, placement/location, and communicative function.

Keywords: Language and disaster, linguistic landscape, Philippines, public signs, Tacloban Typhoon Haiyan

\section{INTRODUCTION}

Multilingualism has been a driving force in terms of pushing scholarship into new grounds. Specifically, the use of different languages in a community can either be viewed as a problem or a resource (Valdez 2011; Phillipson 1992; Pennycook 2010; Tupas 2008). In the case of the Philippines, the existence of several languages remains embedded in a complex web of political, sociocultural and economic ideologies (Tupas 2007). For instance, the existing government policies pertaining to language policy remain controversial due to difficulties in implementation and resistance articulated by different stakeholders (Floralde and Valdez 2017; Gonzalez 2004; Martin 2014). However, the emergence of linguistic landscape (henceforth, LL) sheds new light on the ways multilingualism is employed to address issues of importance in a community. Shohamy and Gorter (2009) define LL as the textual and symbolic display of words and images in public spaces. In other words, the study of LL entails the examination of how signs are produced and interpreted by users and receivers, respectively. Spolsky (2009) retraces the investigation of these urban signs over the past 30 years with the choice of language in multilingual urban space as one of the main topics of interest. Questions on who made such signs and how people chose to represent language and its functions have been addressed in numerous sociolinguistic inquiries, including Spolsky (2009: 25) himself, who regarded the inquiry of these signs as part of a "sociolinguistic ecology of a city." For example, research done on LL has identified underlying struggles between different groups in the community as signs portray conflicts in the value of languages to articulate a community's needs and communicative purposes. The impact of these multilingual signs can be better understood within the notions of globalisation and the spread of English in different parts of the world (Gorter 2006). Multilingualism, then, becomes central to LL studies as it shows how languages become a resource in a community. This paper therefore examines the functions of public signs produced in two communities severely affected by Typhoon Haiyan in terms of materials used, location or placement, and communicative function. 
This paper argues that communicative functions exhibited by public signs produced after a natural calamity are not only motivated by the needs of people or stakeholders, but are greatly influenced by the material and geographical conditions of the senders.

\section{REVIEW OF RELATED LITERATURE}

Research on linguistic landscape reveals the complexities of multilingualism in terms of competing values ascribed to languages, the embedded multimodal features of public signs reflecting conditions of the community, as well as the sentiments of the makers of these public signs.

In terms of competing values ascribed to languages, Lawrence (2012) explored public signs in Korea with the view that social status influences the public signs created in the area and the domain where they appear. Drawing on Labov's social stratification model, Lawrence's analysis, however, shows that social stratification does not fully project a predictable pattern of high incidence of English use in high class areas than in low class areas since there are cities considered as high class but show less incidence of English signages as compared to lower class cities. Also, the dominance of the English language among diasporic communities appear to be an issue in LL research. Leung and $\mathrm{Wu}$ (2012) turned to the produced inequities hidden in public signages of Philadelphia Chinatown, arguing that exploring the non-Mandarin varieties interacting with English in street signages provides an understanding of the "sociolinguistic ecologies of the Chinese diasporic communities" (Leung and $\mathrm{Wu}$ 2012: 120). The study highlights an awareness of how the non-Mandarin varieties could be viewed in terms of diversity rather than of difference and how such an awareness leads to suggest critical pedagogies that would look at public signs as repositories of some hidden inequalities. These studies suggest that while English and other languages may have varying functions and values for a community, public signs reveal that multilingualism in the public sphere provides a sustainable resource for communities to thrive.

Delving on the notion of multilingualism as a resource, linguistic landscape plays a significant role in unpacking the condition of a place. For instance, Papen's (2012) study draws on how the cityscape of Prenzlauer in Berlin is particularly shaped by the processes of urban change through the interspersion of shops on the ground floors and homes on the upper floors. What is significant about Papen's analysis is that Prenzlauer's LL is not just a marketed space but most importantly, a "canvas" that calls for 
social change, as shown in the posters and political graffiti on street walls. Similarly, Lamarre's (2014) study on the verbal play found in the signs along the commercial district of Montreal may be amusing, but at the same time, the signs reveal Quebec's ingenious reply to the city's legal constraints on the use of English. The study also confirms how the speakers capitalise on their bilingual resources, as revealed in the verbal play in their commercial signs functioning either as a "release from repression" (Lamarre 2014:148) or an escape from the normative demands of the English language. Scollon and Scollon (2003) believe that signs in the public sphere reveal indexical and dialogical functions of language in context. That is, signs do not only impart communicative content, but also show relations between communities, as well as underlying relationships between their constituents. Moreover, it is believed that the study of public signs should not be confined to a mere examination of language and its users, but also the materials in which these are used, the placement of these signs for access, as well as the wider contexts in which these messages are produced and received (Kress and Van Leeuwen 2001). For example, space in the production of signs is influenced by location, content and language (Tan and Said 2014). Stroud and Mpendukana (2009) analysed signs that significantly resulted in two types: sites of necessity and sites of luxury. Thus, signs become resources that index wider issues in society (inequality, distribution of resources and political awareness). Bearing these points from the literature, the interest of this present study does not just focus on the influence of English in the locality, but also on how the LL of places in the world opens up to an awareness of the unequal social relations hidden in the produced signs made after typhoon Haiyan in the Philippines.

\section{RESARCH CONTEXT}

Located in the southeastern part of the Philippines, Tacloban City is the capital city of the island of Leyte. Its people regard Waray as the regional lingua franca, Filipino as the national language, and English as an alternate language used in curriculum instruction in schools. The city's official website hails Tacloban as the centre of education in the region with two state universities and several colleges. Its strategic location for business and its port turned the city into a business hub of Leyte and Samar. Today, the population of Tacloban is approximately 223,000 (City of Tacloban 2017) and in 2008, 
it earned its status as a highly urbanised city. Such a newly earned status brought its people the unfolding of a new city with its newly opened upscale mall, the sudden influx of luxury cars, and the opening of popular fast food chains and retail companies that were once only operating in greater Manila, which is considered as the centre of economic and political power in the Philippines.

On the other hand, Palo Leyte is Tacloban's neighbouring town and a gateway towards the southern part of the island of Leyte. It is home to the historical MacArthur landing that marked the Philippines' liberation from the Japanese. Palo's government centre, which houses most of the national government's regional agencies, gives the town an economic boost as there is a regular influx of people transacting in its various government agencies. The town is also home to a developing call centre industry and the emergence of commercial areas in the community.

When the storm hit the eastern region of Leyte, Tacloban City and the municipality of Palo were faced with the often-cyclical task of keeping their residents safe (Renada 2013). After all, storms are regular occurrences in the area, as well as the rest of the country. Yet despite this condition, Leyte-like any other island in a developing country-lacked local literacy on disaster management. Worse, local literacy efforts provided to the locals failed to cater to the complex multilingual characteristic of the people. For instance, local weather experts did not have a readily available description of the tropical storm's destructive capacity in the local language. Hence, the storm brought linguistic problems in the region even before it landed. Two months after the storm, the local print media was loaded with strong expressions of dismay at the tragic death of thousands, putting the blame on the Philippine Atmospheric, Geophysical and Astronomical Services Administration's (henceforth, PAGASA) failure to provide a ready translation of the dangers of the storm (Lejano, Tan and Wilson 2016). Put simply, the locals failed to heed PAGASA's call for evacuation simply because a warning fashioned in English by the term "storm surge" brought them no schema of its impending danger. The radio and local television stations then felt they were not in the position to provide a term that would translate it into its local equivalent, which may have caused misinterpretation on the part of the public. Further, the aftermath of the tropical storm created bigger problems, forcing the people to go out of the streets to reclaim walls of public spaces as their only hope to build their defences. 


\section{METHODOLOGY}

The research sites of this study include the city of Tacloban and the town of Palo. These areas are within the radius or ground zero of the typhoon's devastation. The analysis focused on the signs found in public places: streets, main highways, commercial buildings and public spaces in communities. Over 100 photographs were taken between the months of December 2014 and July 2015 . These photographs were categorised into two groups, namely the locals and the stakeholders, primarily from the national and local government, and local businesses. Also, public signs produced by non-governmental organisations (NGOs) were excluded since NGOs as public sign producers are not primary members of the disaster-stricken community. That is, the signs of the NGOs did not represent the distinct voices that come from the community as they were not directly affected by the Typhoon's effects. From an initial number of 100 photos, 50 were selected for analysis. The selection of the signs is based on the source/sender (coming from members of the community of stakeholders), the clarity of the message shown in the sign (signs that had incomplete messages were not included in the analysis), and the continued existence of the sign after subsequent visits (the principal researcher conducted two additional visits to the sites to examine if the signs were still there).

The public signs were analysed in terms of three criteria: (1) materials used; (2) location/placement of the signs; and (3) communicative function. Moreover, given the sensitivity of the topic of the effects of the typhoon on the community members, the method of "narrated walking" was employed (Stroud and Jegels 2014). Specifically, as an ethnographic approach, narrated walking intends to examine informants' views about public signs. While places are geographically fixed, inhabitants continuously construct meaning through their personal experiences of place in relation to signs they see. Given the emotional consequences brought about by the natural disaster, it was deemed appropriate to employ narrated walking as a means to examine interviewees' insights about the public signs they produced after the disaster. However, a limited number of interviews were retrieved from the business group since only a few of them agreed to share their retrospection while others opted out. For the stakeholders (specifically businesses), the interviews probed on the communicative purposes of the signs produced on their part. Also, interviews with the locals were also sparse since most of these sign producers eventually abandoned their homes. Specifically, reasons for creating the signs were probed during the interview. Storm survivors who stayed to witness these signs and who weathered the period of recovery were interviewed to address this matter. Due to the descriptive nature of the investigation, the materials used and the 
location/placement of signs were identified. However, for the communicative functions of the signs, the concept of intended meaning was analysed (Gorter 2006). While the signs' communicative functions can be categorised in terms of the source/producers, the interview data of those who viewed these signs served to establish validity in the interpretation.

\section{RESULTS AND DISCUSSION}

The succeeding sections discuss the results of the data analysis. Specifically, the public signs produced by locals and stakeholders after typhoon Haiyan in terms of materials used, placement or location, and communicative intent are described here.

\section{Materials Used}

The materials used by the locals in producing their signs come from scavenged scrap. After the storm, the locals were left with storm-tattered metal sheets, scrap boards, or storm-ravaged boulders. These materials eventually served as their material in writing distress calls for assistance and help. As shown in Figure 1, the tempered effect of its utmost economy is bolstered by the bold streaks of paint that read: "HELP SOS FOOD WATER." The hand-painted script obtrusively bleeds, as if the strokes express a sense of urgency and need.

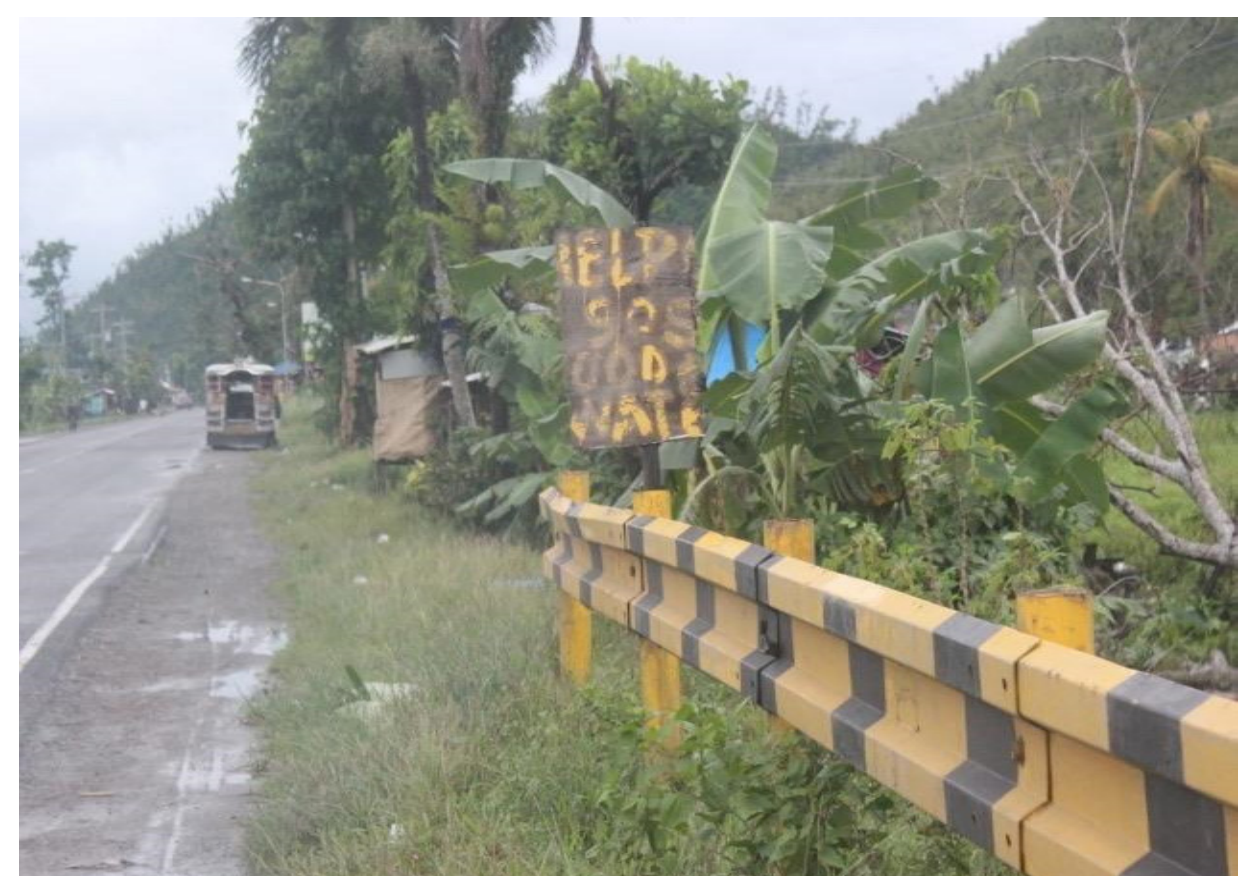

Figure 1: Roadside call for help. 
The locals' signs bear simple messages written by hand, which express a transactional function indicating a desperate plea for assistance.

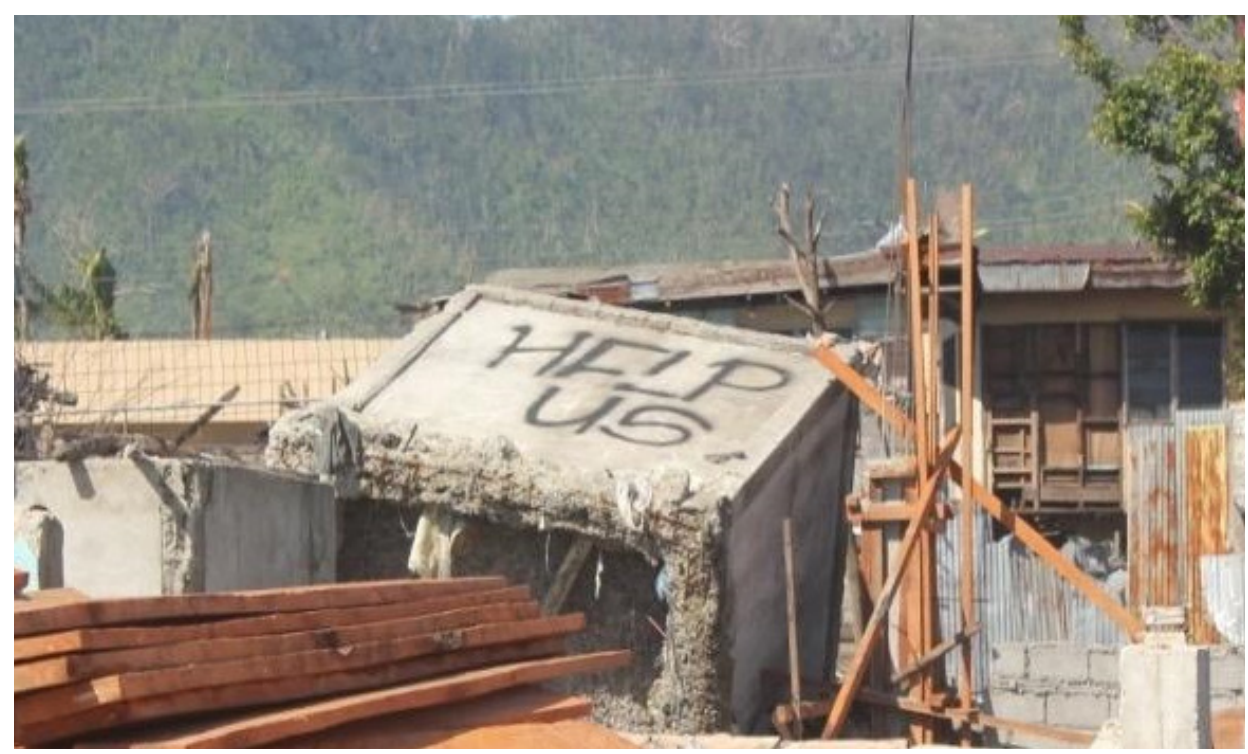

Figure 2: Appeal for help.

An interesting observation is the universal appeal of the English code used to express distress calls such as "Help (us)" as shown in Figure 2. The call that is scripted in English clearly reveals how the English code is used in the local environment (Blommaert 2010). Despite its rich multilingual character, the Philippines' colonial history with American rule has resulted in the spread of English throughout the country (Martin 2014). This spread has permeated the controlling domains of society (education, government, business), rendering English as a second language. In the context of the sign, the use of English does not only indicate the locals' familiarity with the language, but can also be interpreted as a sign that intends to reach a wider audience due to the language's global character.

For the stakeholders, aside from being produced using finer materials, the signs are not created by hand, but by machines. They are usually printed in tarpaulins that are wide enough to be seen even at a great distance. The signs are printed using colored fonts, pictures and figures effective enough to catch the attention of people. Resulting from greater sophistication in production, these features of the signs reflect the stakeholders' intent to fully exhaust their resources to maximise the signs' meaning potential. That is, to promote the businesses' interests in the community.

In Figure 3, Camella Homes, one of the leading realty development companies in the country, launched a public sign in the Waray language that reads: "Stand up Leyte. We stand by you!" The script is printed on a 
tarpaulin that spreads several meters wide and stands about 15 feet high. The colourful company logo is juxtaposed with the text in the word Bangon, which is a Filipino term for stand up, and the Waray expression Kaupod nyo kami. The use of both the regional lingua franca (Waray) and Filipino add local flavour, sending a sense of empathy to local clients.

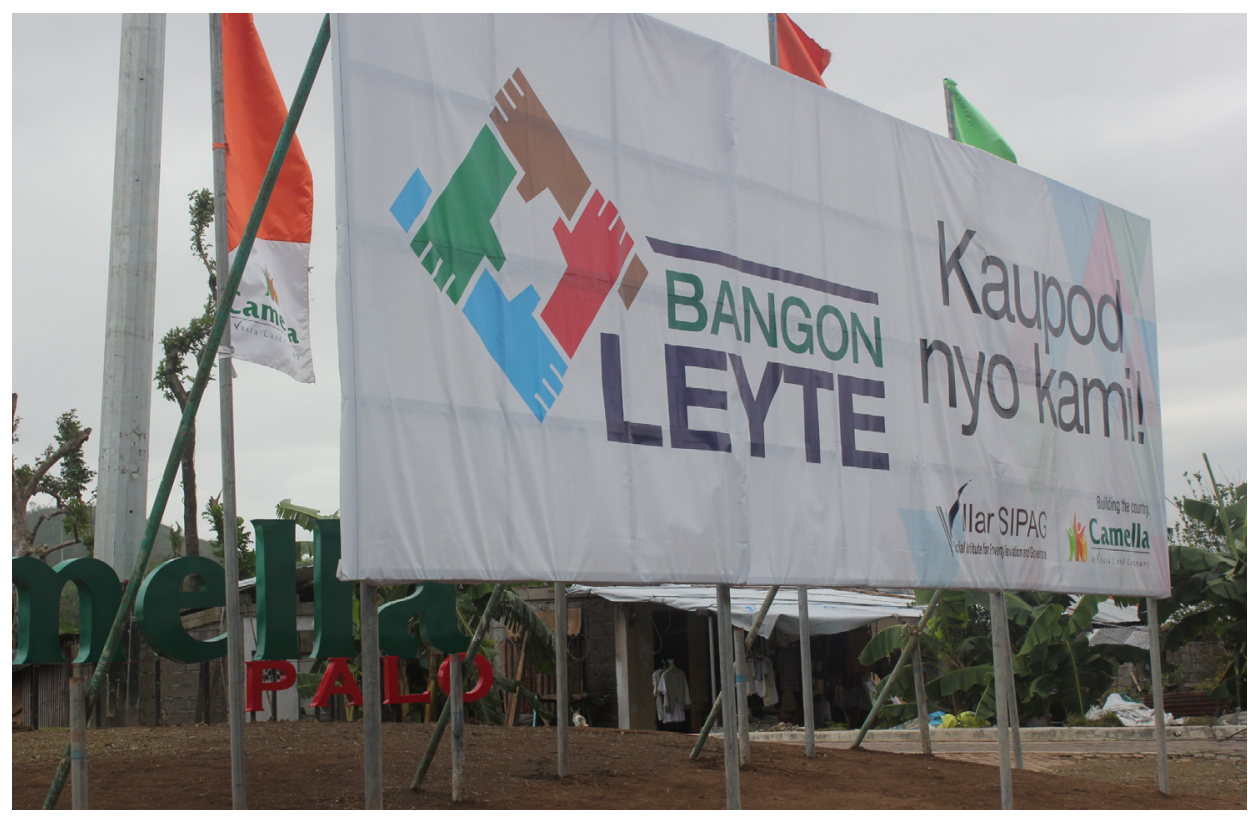

Figure 3: Realty signage.

Moreover, signs by the stakeholders are styled to perform a hybridised function. That is, the signs analysed have several communicative functions which indicate underlying agenda amidst the communicative purposes the signs initially entail. What is interesting in their signs is that these undergo editing and are produced with caution. Unlike the signages produced by the locals, the signs produced by the stakeholders are carefully schemed for production that includes several phases of lay-out revisions, text font and even the choice of language employed. The greater resources of the stakeholders provide them with the capacity to reproduce the signages with the aid of technology. For instance, ISUZU Tacloban had to revise their signage several times before the final version was approved for posting. As claimed by one of the employees, the car company originally thought of using the local language in the signage, but earlier versions were too wordy. They then revised it, resorting to English, but decided to include the local mantra TINDOG which means "stand up" as their way of showing empathy to the typhoon victims, which included some of their clients. Some other companies resorted to English as the global code, while some others employed the codemixing of English and the local language. 
In addition, the signages bear labels of ownership. The signages of the stakeholders always bear the name of the company because these are not just signages of hope but also acts of promoting their business agenda, which indicates a hybridised communicative function. Thus, while they invade public spaces to address the public with their call for action, these displays also doubly function as a branding strategy. In Figure 4, the name of the car company positioned at the topmost part of the tarpaulin marks identity and ownership of message. The inclusion of its photographed facade sends an assured visibility of the company in Palo, Leyte. It is important to note that the car company was due for a grand launching on the same month before Haiyan struck the island. Hence, the photograph contributes to the delivery of the message of solidarity and patronage. Captioned all in bold capital letters that reads: "HERE TO STAY STAND STRONG EASTERN VISAYAS," the signage results in an aggressive voice of resilience and competition despite the destructive effects of Haiyan. In an interview with one of their representatives, Nissan-Tacloban recognises English as a preferred global code to carry their message of hope. However, while the strong message of hope is successfully delivered through the tarpaulin, the sign comes with a hybridised function. That is, to promote the company and attract prospective car clients. This is evidenced by the contact numbers displayed at the bottom part of the signage to cater to client inquiries.

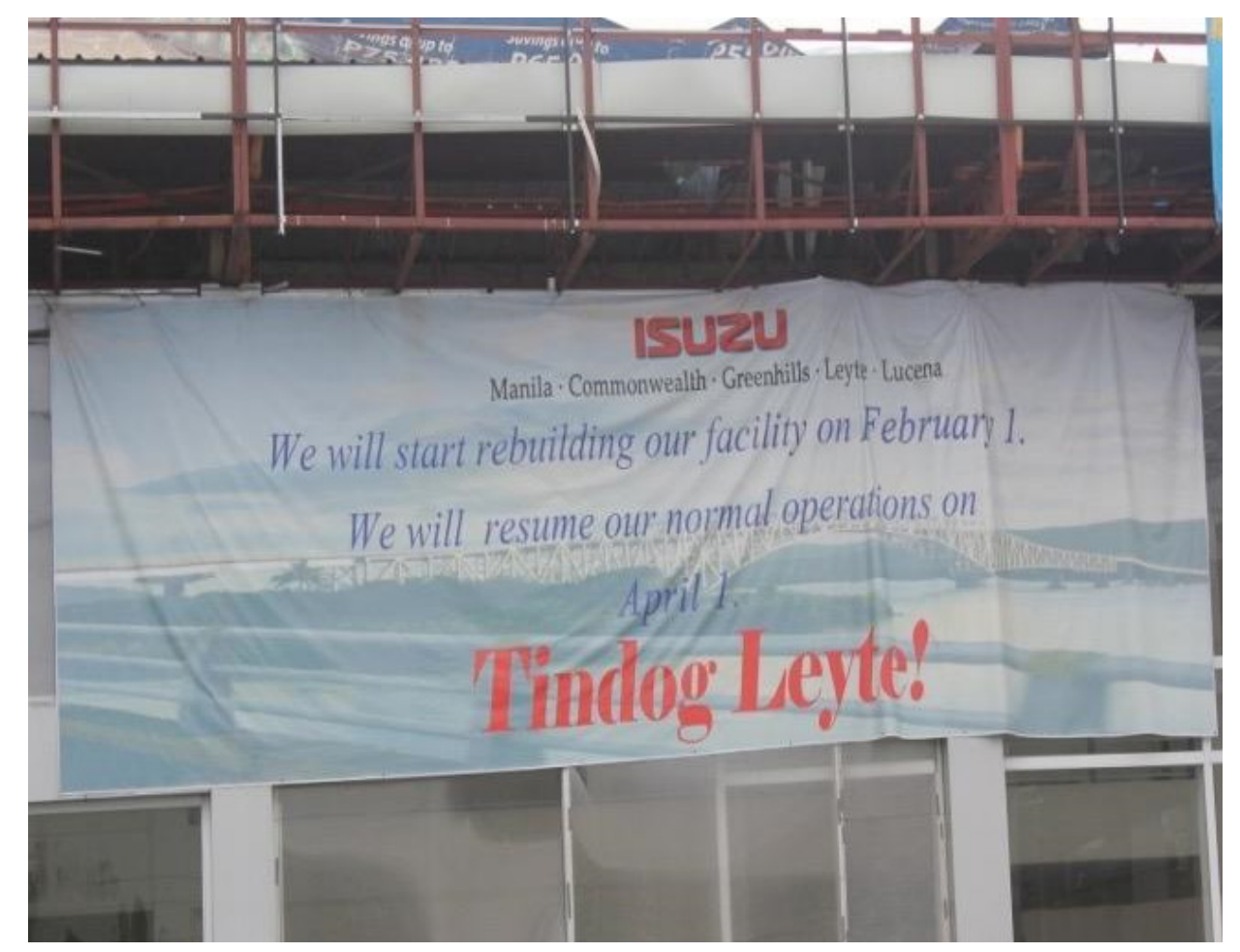

Figure 4: Isuzu Tacloban sign. 


\section{Location/Placement of Signs}

For the locals, their signs occupy the peripheral areas. While signs are generally placed on higher planes to gain public attention, this is a difficult requirement for the locals who are without the luxury of materials. Instead, the locals took advantage of every roadside to position their public signs on the peripheral side sweeps of the road. Some could only make use of space no higher than the public wall, as shown in Figure 5.

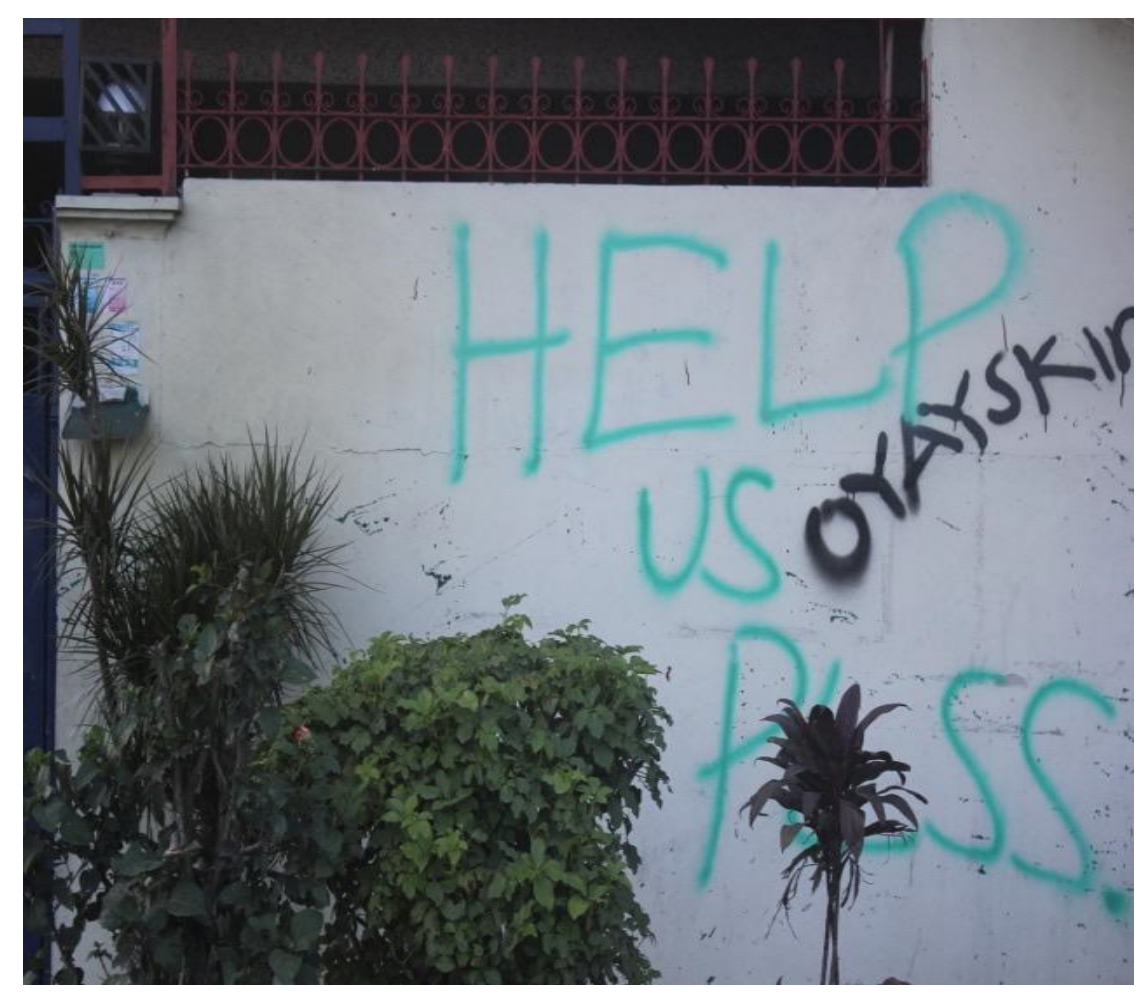

Figure 5: Distress on wall.

The economy of materials and the downward confinement of their public signs all point to the conditions of the speakers. Blommaert (2010) observes that the speakers' marginalised resources dictate their trajectories. Such observation is confirmed in catastrophic occurrences where their trajectories are pulled down even more. A more interesting signage is shown in Figure 5 with the distress call written on the storm-torn wall of one of the flattened rows of the fishermen's houses along the Magallanes coastline. Similar to the other signs of the locals, this particular sign is confined to the rubble. Hence, as the cataclysm wrestles them to the ground, so do their signs.

On the other hand, the signs of the stakeholders enjoy spaces in prime locations. Unlike the signages of the locals, the signages of these institutions enjoy premiere sites, such as major highways and crossroads that are usually 
accessed by most motorists. Also, these signs are put up in higher planes, such as on top of high-rise structures or placed in a customised frame set high enough to be seen by people. In Figure 6, for instance, the signage is raised by a scaffold for everybody to see. Its magnanimity is strengthened by the presence of halogen lamps that provide ample lighting at night. The placement of the signage in the middle of a major crossroad in the city reveals how the company continues to hold power amidst a natural calamity. In an interview with Natasha Tacloban, the company reveals that the need to put up a sign high up for everybody to see is because their dealers kept on asking when they would open. The large size and increased height that the sign occupies assert the wide reach and the assertive claim that the company is never afraid to project. The upward trajectory of the signs is a common feature among the signs of the stakeholders.

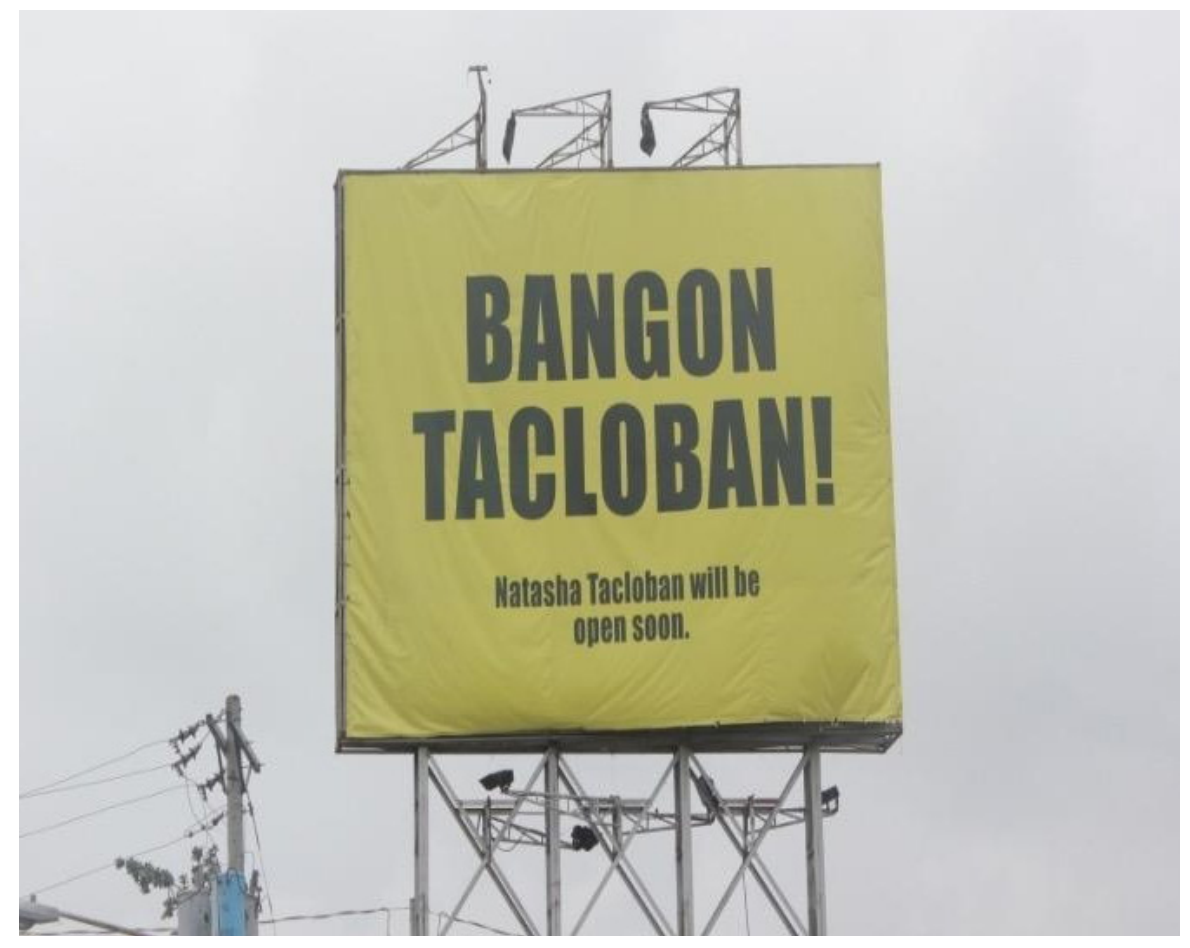

Figure 6: Bangon Tacloban (rise up Tacloban).

\section{Communicative Functions}

As regards to the communicative functions, the public signs produced by the locals express gratitude, assert territorial control, and question social order.

In Figure 7, the public sign functions as an expression of gratitude using the English code. In looking at the signs, one is led to the idea of how the English expressions contained in them become part of what Blommaert (2010: 149) calls "new forms of multilingualism" where English use is "effectively 
minimal." The appropriation of the English code is understandably aligned with the context of devastation wherein help is sought from the outside. Haiyan, being the strongest tropical cyclone of the century, headlined the world. As it crippled ground zero, the use of English in some of the signs functions as a language of wider communication that sought to address not only the multilingual population of the Philippines, but also possible benefactors outside the country. This is evident in the public sign shown in Figure 7 that addresses one of numerous international benefactors. In this sign, English becomes the recognised universal code to express the gratitude of the locals. Still, even in this signage, the trajectory is downwards, placed along stretches of debris in the neighbourhood. Delving on this trajectory, it can be inferred that while the use of English allows the locals to express their gratitude to foreign aid, their impoverished conditions remain.

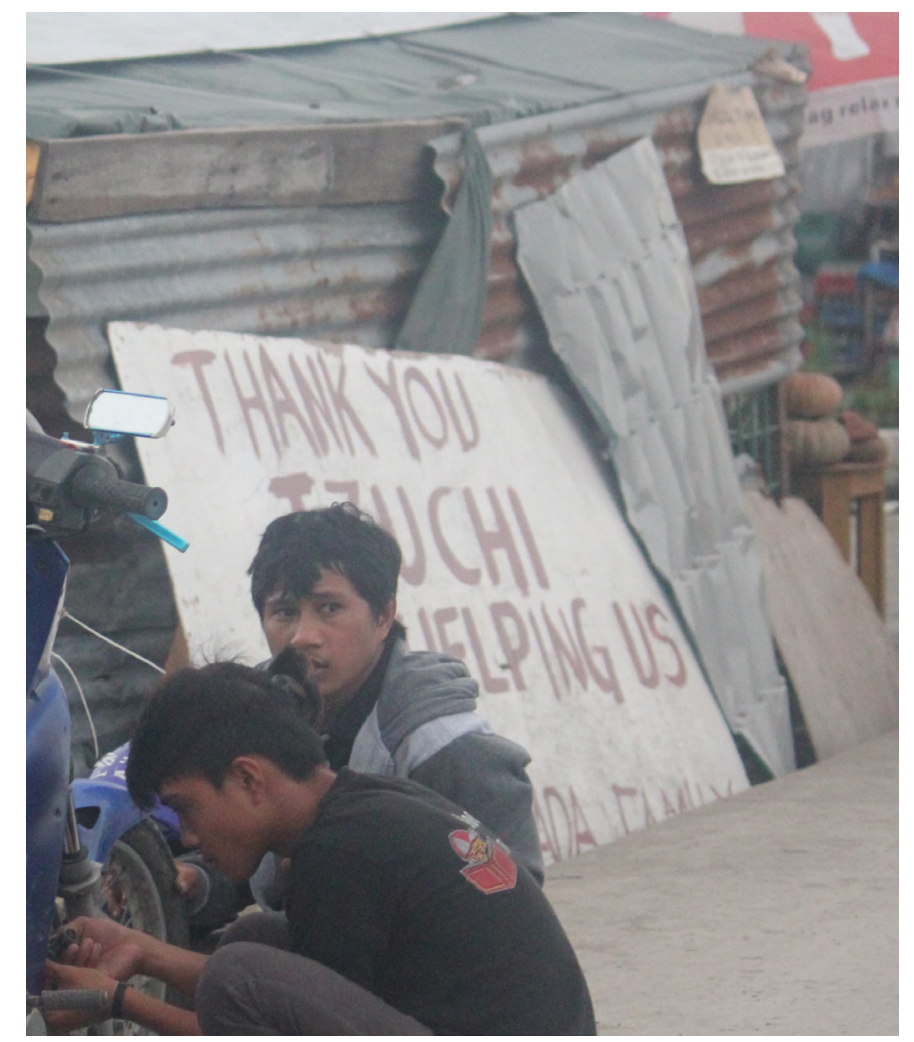

Figure 7: “Thank you Tzu Chi."

Analysis of the signs indicate that they express dialogicality. This means that these public signs intend to communicate to a specific audience for a specific intent but is addressed to all viewers on a wider space. In these urban spaces, graffiti plays a significant role in "the discursive creation of the landscape" (Pennycook 2010: 67), with the public space undergoing reinvention. As such, the walls where personal messages are written to reach their long-lost loved 
ones are commonplace. As shown in Figure 8, the Waray script which reads: "Trisha we will wait for you. Your cousin" reinvents an open letter from paper to walls. Trisha obviously is the lost relative, and the cousin becomes the informant. The same call is repeated on the metal sheets that read: "We will wait for you. 8AM to 5PM." This sign clearly manifests how typhoon victims of Haiyan were able to build their defences by compressing the public space to its rescaled function of connecting and reuniting with lost loved ones. In this case, the public signs serve as a call to a specific person and perhaps, an indirect appeal to others who may know the whereabouts of the person needing to be located. When electricity was unavailable and electronic forms of communication were absent, the public walls served as message boards that somehow reduced the distance between people. The locals marked public spaces by making use of graffiti and scrapboards to express their current state. In Australia's cityscape, graffiti is reduced of its notoriety and "criminalisation" (Pennycook 2010: 58) and is rescaled as "public art." But in the context of a disaster, graffiti undergoes rescaling wherein it no longer functions as that of "adorning a public space" (59) but as a resource for communication. This rescaling is interesting because in the face of adversity, the walls become inviting resources to bear expressions of the vulnerability of people.
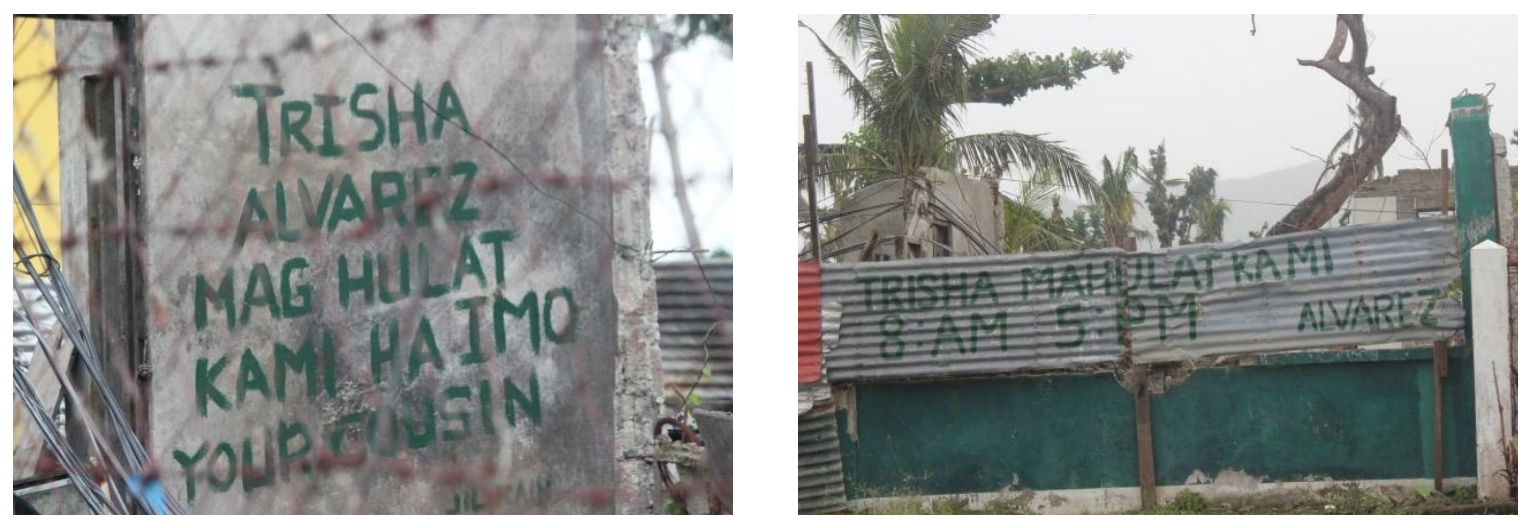

Figure 8: Rescaled graffiti.

The public signs of the locals assert measures for territorial control. The aftermath of the tropical storm brought chaos that threatened the security of the locality. In their attempt to protect themselves from social disorder, the locals countered by relying on public spaces to employ measures of territorial control. The use of the language becomes a powerful tool to emphasise the people's defences. For most of them, the use of the local language reveals that the message is directly addressed to local outlaws. For others, code mixing in Filipino and grassroots English are employed. However, even when their 
safety is being threatened, the locals could only assert their defences within the limited resources they could make use of. The graffiti in Figure 9, which is translated as: "Do not enter" is produced with a goal to write on the gate wall. Such attempt to elevate an oral language such as Waray into writing makes it all the more chaotic as shown in its problematic syllabication on display. The signage is left in its unedited, spontaneous and destylised form, and the strong message is forced on the reader to decipher.

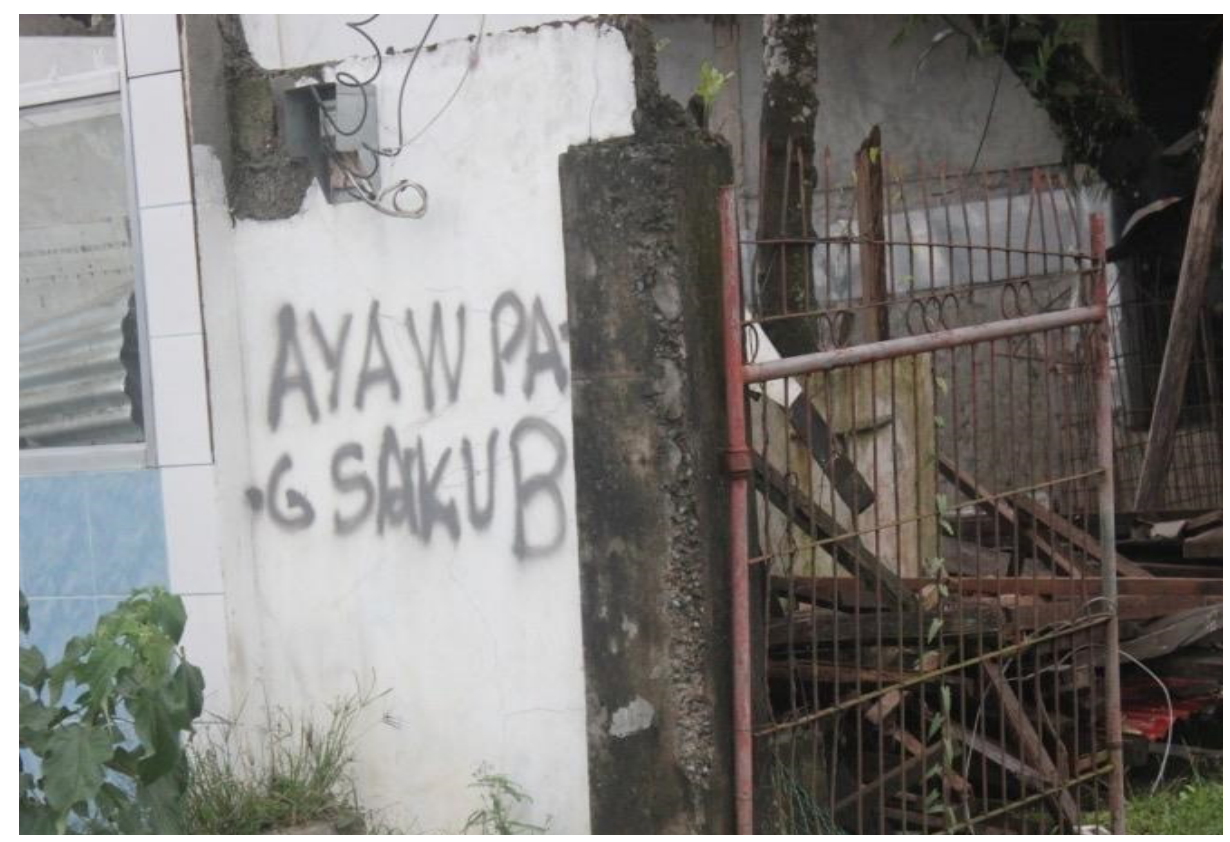

Figure 9: Sign of territorial control.

As shown in Figure 9, the public signage sends a warning to any intruder of any attempt to trespass (Ayaw pag sakub - Do not enter). Although the sign bears no sense of ownership, the time indicated on the sign immediately signals to the reader that the blockade is not just to protect one residential structure, but an entire village. Such a sign voices out a collective act to protect the entire community. In Figure 10, the expression (Babala wag papasok - Warning to everyone. Do not enter) SHOT TO KILL, which somehow attempts to encapsulate the severity of the message, is a grassroots counterpart of the English expression SHOOT TO KILL. Such an expression attests to the spread of English in the locality but reveals how this expression has been localised. This observation is similar to Blommaert's (2010) assertion that grassroots literacy draws from truncated repertoires of speakers who may be unfamiliar with rules of use but rather approximate linguistic utterances of a second language (in this case English) to articulate their communicative purpose. 


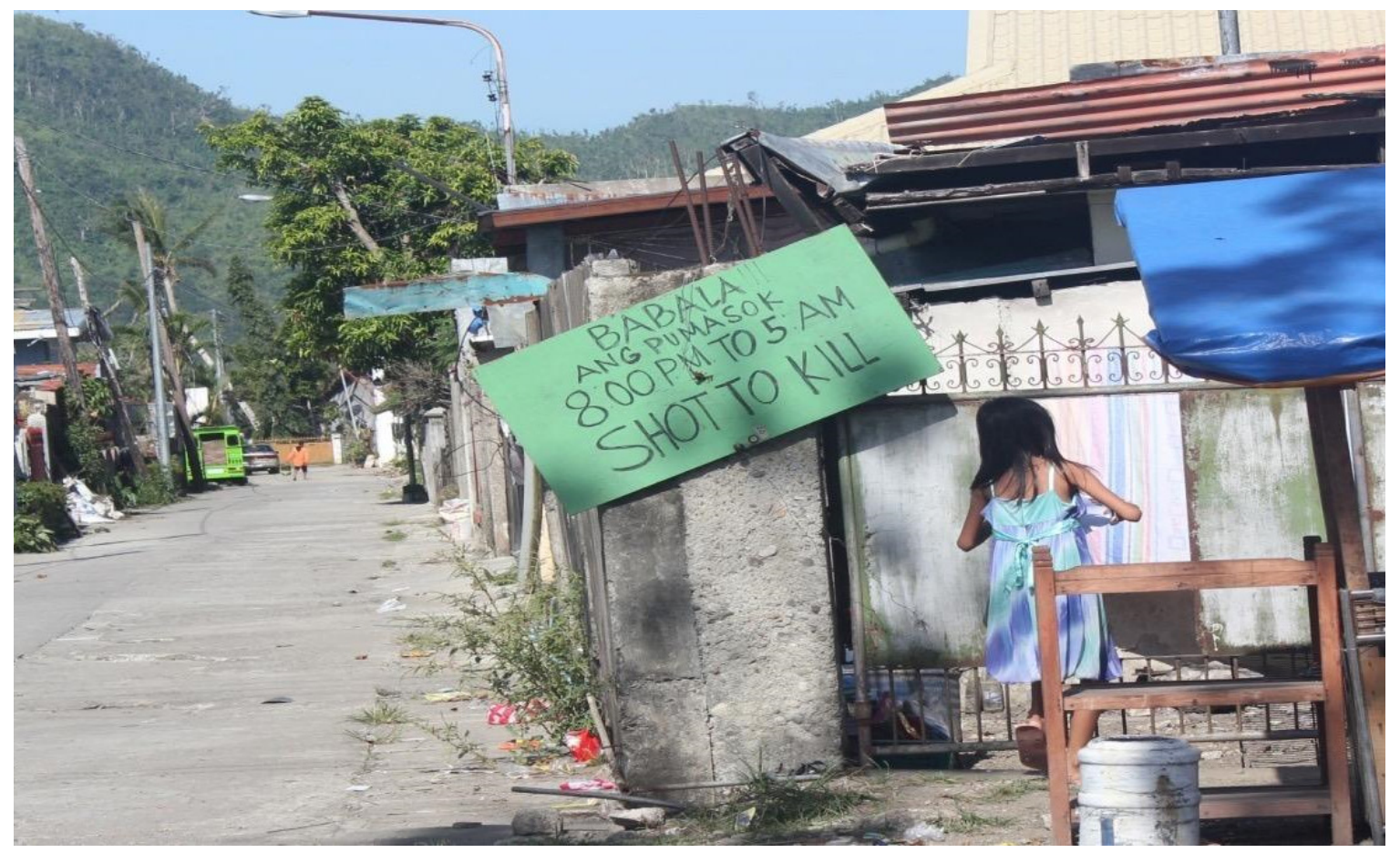

Figure 10: Village sign.

Another function observed is that the public signs question social order. The urban displays created by the locals are characterised by nonchalant criticisms of social order. Their knowledge of the English language, as well as the national language, becomes weapons to criticise, assert, ridicule and resist existing social conditions brought about by the aftermath of the tropical storm. The Filipino sensibility reveals how wordplay is ingeniously used to criticise the way social organisations operate mobility. Unlike the verbal play analysed in Lammare's (2014) study, most of the signages produced by the locals come uncautioned and dauntless in expressing and exposing what they believe as inefficiencies and incompetencies of government agencies. In Figure 11, for instance, the acronym DSWD, which originally stands for Department of Social Welfare and Development, was ingeniously changed to a Filipino counterpart which translates to: "No relief goods reached us"-a reproach to the agency's poor performance in disaster management. Also, the use of the English phrase relief goods in Filipino reveals the locals' ability to reinterpret acronyms to question social order. Such use reveals the predilection to loan words, especially from the English vocabulary to the Filipino language. Clearly enough, the term "relief goods" has no direct equivalent in Filipino. If there is, it is seldom preferred because of its lengthy nature. The borrowed words make it sound better because they are short enough to fit in the reclaimed plywood. 


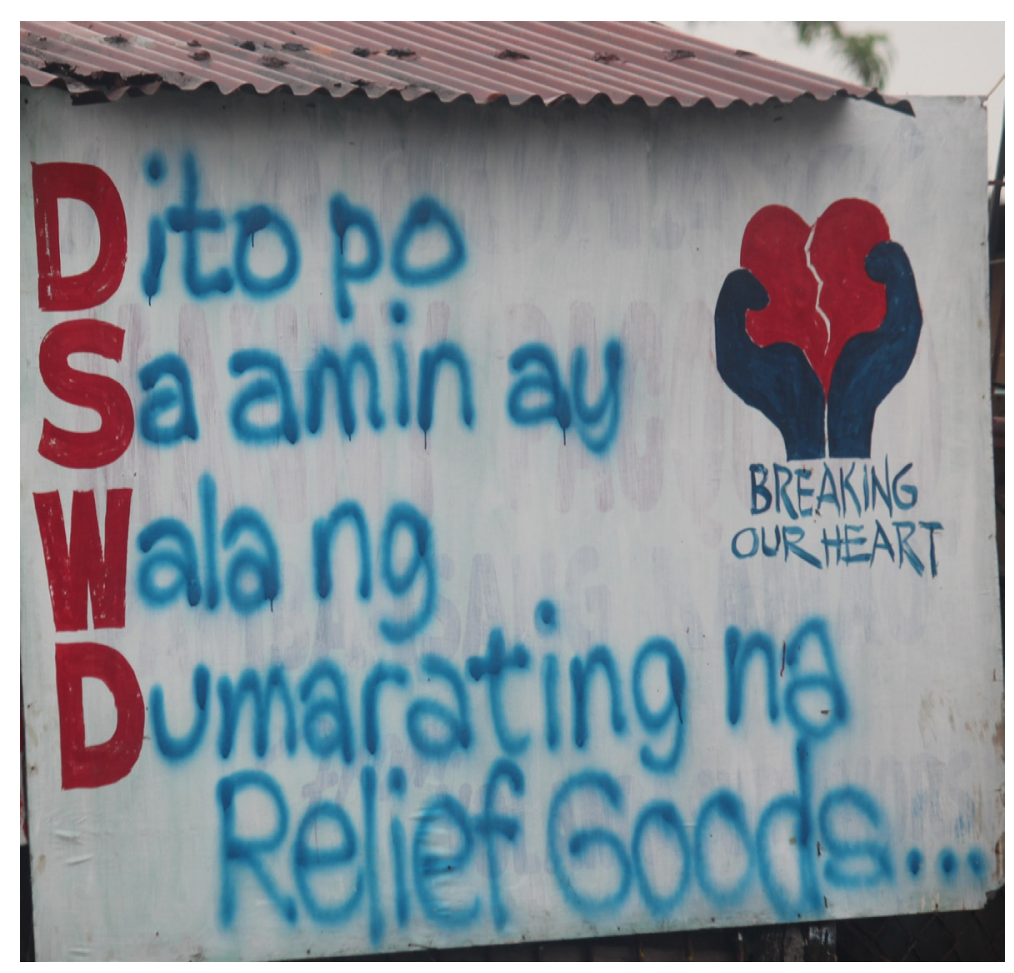

Figure 11: Signages of social change.

In addition, as seen in Figure 11, the inclusion of a broken shape of a heart labelled with the English expression "breaking our heart" reflects the parochial sentimentality of the locals. An attempt to prefer its wordy Filipino equivalent will most likely require too much space in the already-scrimped material. Expressions such as "breaking (my) our heart" are often picked up from English love songs and romance films that reach the locals. The meaningencapsulating capacity of the English expression often becomes a practical option over Waray in meeting the demands of the scrimped material. Also, the emotionality of the expression creates an exaggerated pun that alludes to their distressed condition. In addition, the rescaling of the acronym of DSWD (which originally stands for Department of Social Welfare and Development) is changed to an indication of the absence of relief goods in the locale. The rescaled version is translated to "Here, we have not been receiving relief goods." One local (Albert) who was interviewed about the reasons behind the production of the signs asserts:

I see these signs as distress calls. Specially during the first few days, the signs say "help us," "retrieve the dead bodies," but as the days turn to weeks and months, the distress call became complaints. You see the agitation, the frustration. I could feel for them because I was part of the complaining public... 
The signs usher strong collective consciousness. The urban signs created by the locals bear strong voices that bash disintegration. Interestingly, the semiotic scrapboard display in Figure 12, aided by the symbolic image of Pacquiao (a popular Filipino boxer), projects an unwavering mark of identity of the victims as one, asserted especially in times of distress. This sense of collectiveness is explained by the commonality of their signs that bear no sense of ownership. The utmost economy of the signage, however, could only conquer peripheral spaces. Most often, these signs are marked by their limited resources that define their status.

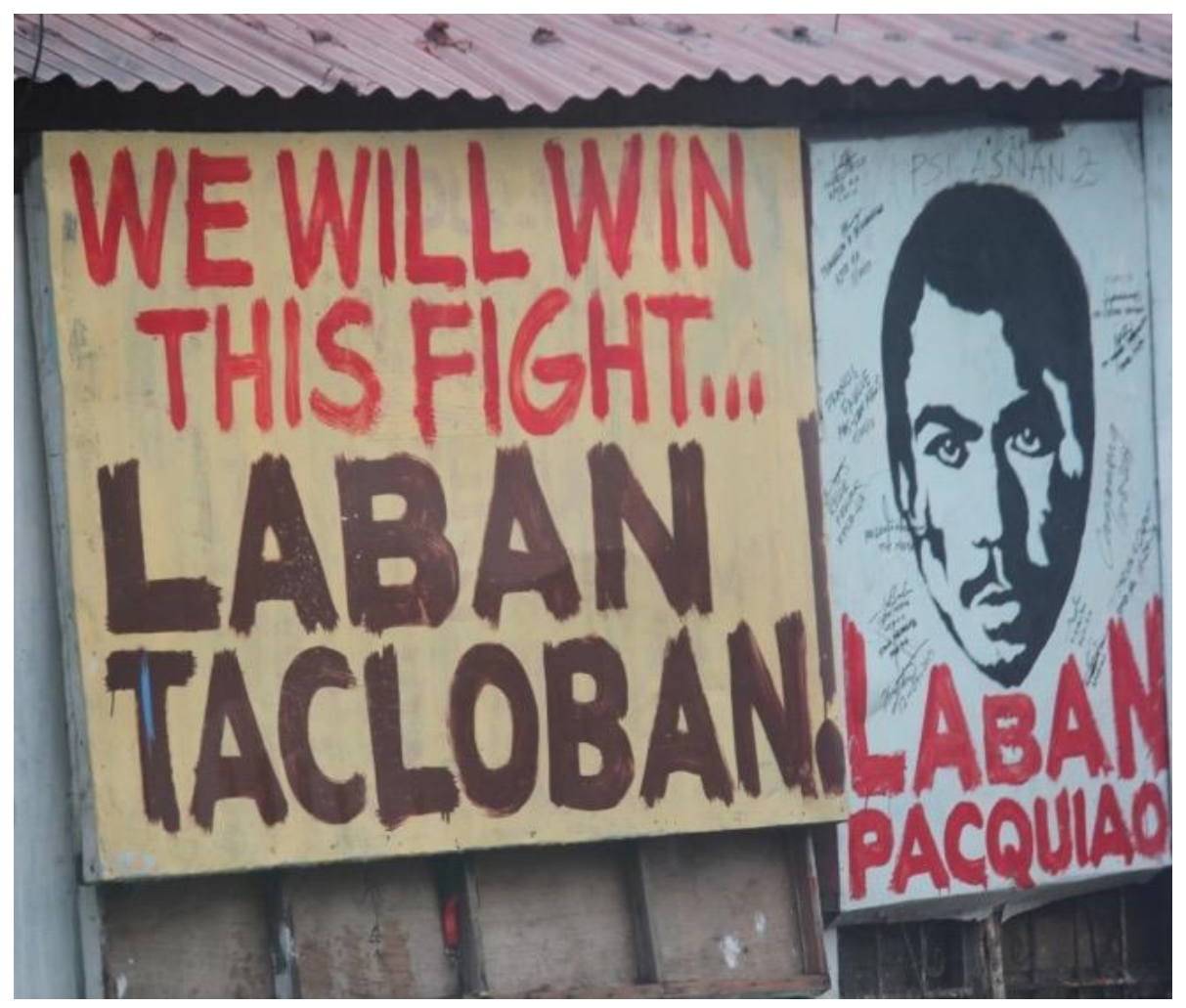

Figure 12: The Pacquiao message.

Also, Figure 12 employs local artistry-a skill crafted by hand, perfected through apprenticeship. Such art, unfortunately, is now slowly disappearing due to the advancement brought about by digital printing. Echoing Pacquiao's mantra, the employment of codemixing (the use of Laban or Fight) of English with the strong appeal in Filipino, the country's national language, as well as the positioning of Manny Pacquiao's caricature, produces a representative semiotic display of solidarity among the locals. The materiality of the signage emblematises an identity marker for the masses who become easy prey in times of adversity. To support this, one of the locals who produced the sign gave reasons for including Pacquiao: 
These languages are like second skin. People were used to hearing and speaking them in the locality and recognised their practicality. His [Paquiao] wide acceptance, I guess, would provide the signs with more impact on locals who would read them. ...It was timely that Pacquiao's fight was all set after the devastation so I thought it was best to use Pacquiao's image as a symbol of hope. When humanitarian help came earlier than the government aid, I noticed that the locals depended on such help. They embraced this nothingness so well that they refuse to take action. They slackened. They even stopped cleaning their own backyard.

As a whole, the public signs produced by the locals were the first to come out because they immediately felt the devastation. Such signs were mostly distress calls that included asking for the most basic of human physical needs, as well as seeking assistance for the retrieval of lost or displaced loved ones. Hence, the economy of their signs can be attributed to their material conditions after the calamity. Moreover, the functions of the signs of the locals can be interpreted as communicative expressions for survival and security.

\section{FUNCTIONS OF SIGNS OF THE STAKEHOLDERS}

As discussed earlier, while the stakeholders' signs are a product of greater material resources, the communicative functions of their signs display show hybridised functions. The signs purposively communicate concern yet promote business interests which are addressed to a greater audience. Moreover, specific functions were also observed. The signs of the stakeholders assert measures for business control through an information drive. In times of crisis, the public space becomes the fastest and most effective tool to communicate to the public. The urban signs, either in English or a mix of English and Filipino because of the multilingual milieu they are in, require a level of neutrality in representing their message. Their signages extend their marketing function to the maintenance of an informed and satisfied business clientele. For this kind of signage, dates of resumption of business operations were important data that would satisfy the querying clientele, as shown in Figure 13. However, information-giving in a multilingual environment proved to be challenging. In an interview, Isuzu-Tacloban admitted that the signage went through considerable rehashing before the production of the final version. While attempts were made to employ the local language Waray, Isuzu-Tacloban shifted back to English because the wordy Waray version resulted in a much 
longer text content. Seargeant and Tagg (2011) refer to this as a dilemma of observing "modes" (501), referring to how certain discourses are constrained by certain features such as message size.

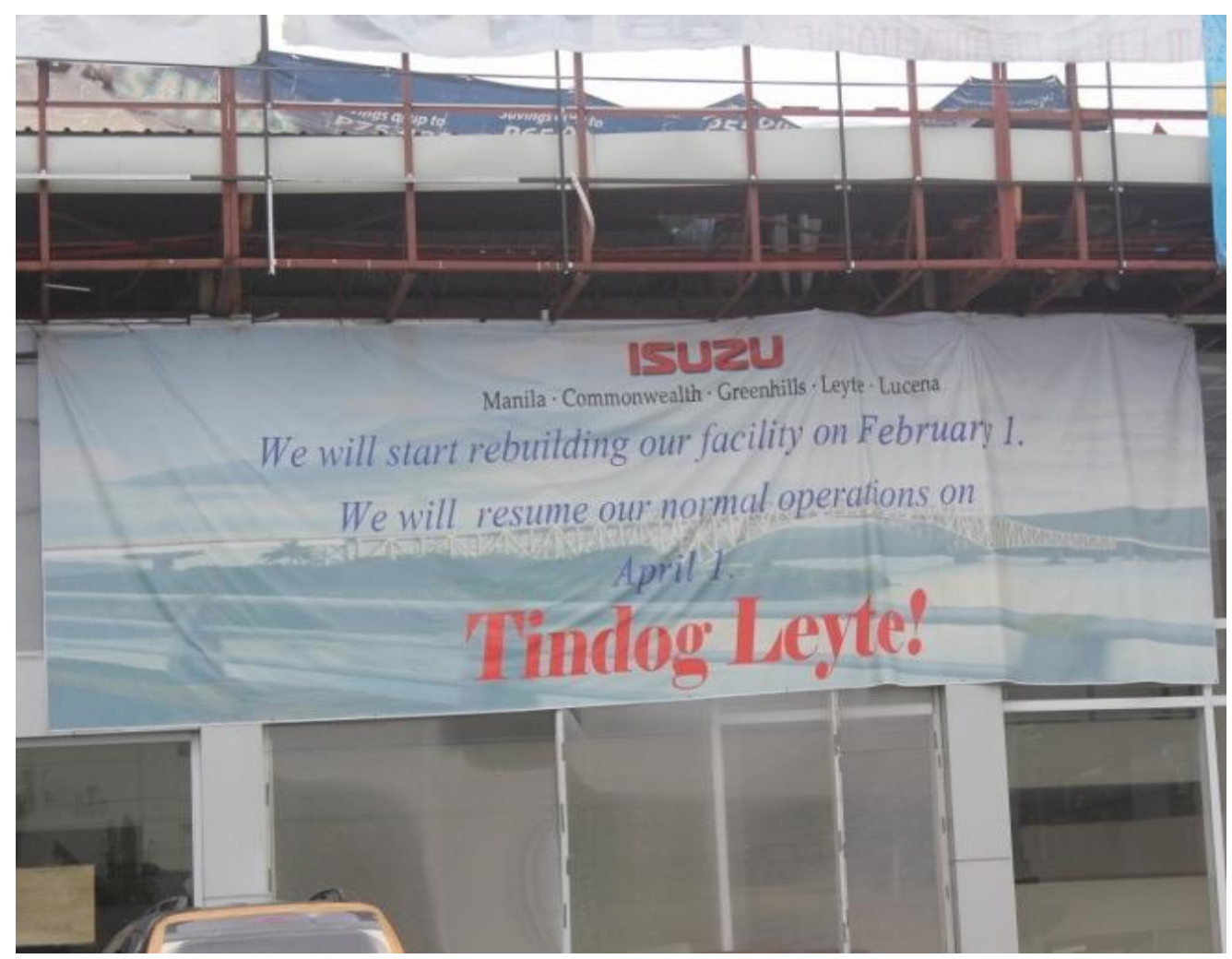

Figure 13: Isuzu-Tacloban.

In its final product, as shown in Figure 13, Isuzu-Tacloban relied on English as the code that efficiently delivered information but had chosen to retain the mantra Tindog Tacloban (Stand up Tacloban) to express empathy and encouragement to the people because they believe that words of resilience are genuinely felt when they are expressed in the language that the locals speak.

The signs of the stakeholders usher normalcy through business continuity. The signs contain a reassuring tone that normalcy has already been reclaimed. These business signages are taken as a means to counter desperation. In an interview with one of the locals, Pagliawan, a book author, local poet and educator, claims that it was easy to lose hope during the most trying months after the typhoon, but seeing these verbal displays gave both the stakeholders and the locals a boost of optimism.

What is interesting in these displays is that they have created their own discursive practice. For instance, the verbal display Tindog Tacloban (Stand up Tacloban) is a local expression that calls for action and can be interpreted as a response to adversity amidst the devastation of the typhoon. 


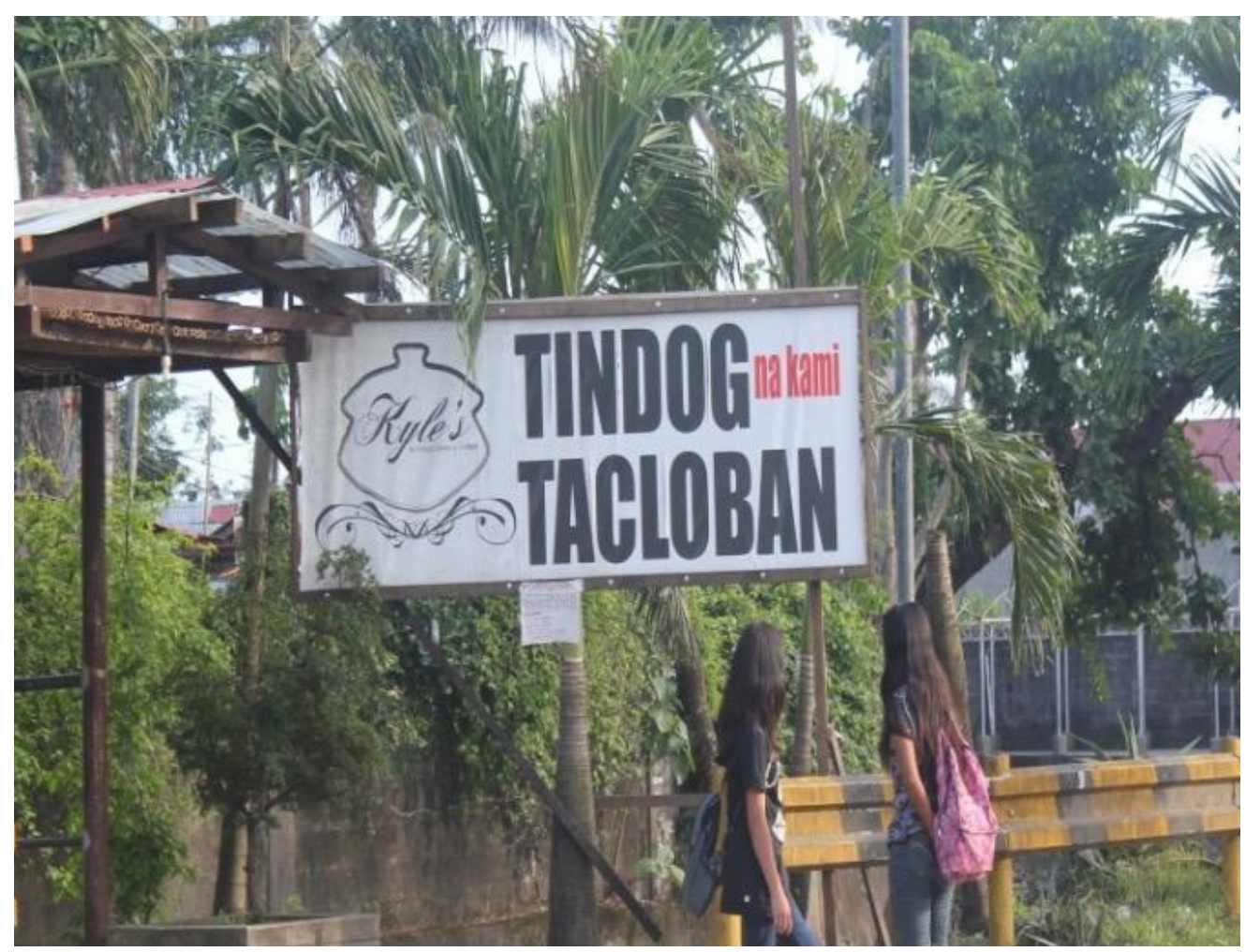

Figure 14: Kyle's Restaurant.

As shown in Figure 14, Kyle's, a local restaurant, re-opened its doors to its patrons three months after the devastation. In support of the Tindog (Stand Up) movement, Kyle's signage fuses creativity through the use of the local language (Waray) to indicate that they are not only open for business, but has also recovered from the typhoon's aftermath. The tarpaulin is free from other promotional tools such as contact numbers for client queries. No other features could identify the restaurant except for its logo. The signage is a hybrid of its marketing function and its advocacy on recovery. These are merged in the texts that are read horizontally for its promotional function in the Waray language: Tindog na Kami, which means "we have stood up." The expression seems to respond to the call to action and that the restaurant has risen from the destruction. Read vertically, the signage sought others to do the same: Tindog Tacloban (Stand up Tacloban), a call that hopes to amplify the resilience of others. Though Isuzu-Tacloban (Figure 13) and Kyle's (Figure 14) messages appear to have the same underlying communicative functions in their signs (calls for solidarity and resilience while advertising the businesses), its features have salient differences. In terms of materials and wider spaces to transmit their respective messages, Isuzu, being a global brand, has greater sophistication and detail in presenting their message. This can be seen in the variety of colours, fonts, and added details in their sign. On the other hand, 
Kyle's sign is rather limited in terms of the details rendered and materials used. The findings suggest that while both signs have the intent of promoting the business, their trajectories are limited to the resources that they have at their disposal (Blommaert 2010).

\section{CONCLUSION}

The linguistic landscape of Tacloban and Palo resonates how the resources of their people are instrumental in expressing a range of communicative functions. Given the conditions brought about by the typhoon, the existing resources available to the locals, as well as the social institutions, dictate the kind of signs that they produce. The locals created urban signs that are limited and peripheral. On the other hand, the stakeholders produced signs made of finer materials and are lodged on prime spaces. While the trajectories of the signs produced by the locals trudge below, the visuals produced by the stakeholders maintain an upward trajectory. As seen in the investigation, the locals produced signs that attempted to appeal to authorities to address their immediate concerns, such as the need for basic goods and services and immediate security from looters and trespassers. In addition, the signs produced by the locals served to communicate with family members who might have been lost during the disaster. On the other hand, stakeholders produced signs that attempted to promote solidarity and hope for those stricken by the tragedy.

Finally, the two groups of sign producers have conquered public spaces differently to serve their respective goals. The locals produced signs that are upfront, assertive, strong and created without caution. On the hand, the capitalists produced signs that are carefully structured, stylised and rendered with restraint. They are products of careful planning because underneath them is an aggressive marketing function. What is common in the signages, though, is their dialogic capacity to connect with each other with one common goal, that is to rise with resilience amidst adversity. Moreover, as this study has demonstrated, the use of LL shows the potential of multilingualism as a resource in not only addressing immediate needs of a community during a disaster, but also forwarding wider agenda that may be interpreted as capitalising on the vulnerabilities of people stricken by disaster. Despite some problematic issues with the production and reception of signs, there needs to be greater work in developing multilingual/multicultural awareness in dealing with natural disasters for an improved response in reducing the damage of calamities on communities. For instance, the scientific community, together with community 
members and language experts, should collaborate on developing accessible information networks employing different languages in reporting weather forecasts or information related to natural disasters.

\section{ACKNOWLEDGEMENTS}

This paper is respectfully dedicated to the late Dr. Danilo Dayag, former chairperson of the Department of English and Applied Linguistics, De La Salle University, Manila, Philippines. This research received no grant funding from any agency in the public, commercial or non-profit sectors.

\section{NOTES}

* Glenda Doroja-Cadiente received her bachelor's degree in Secondary Education majoring in English from Leyte Normal University the Philippines in 1996. In 2000, she took her master's degree in English Language and Literature Teaching at the Ateneo de Manila University. She is presently an Assistant Professor in the Language and Literature unit of Leyte Normal University. In 2014, she was awarded a scholarship to pursue a doctorate degree at the De La Salle University-Manila. As a doctorate student, she has also presented papers in local and international language conferences. Her major interests are on linguistic landscape and institutional talk. She is currently doing her dissertation writing on death reporting in the Philippine health sector, analysing features and tension of doctor-informant interaction as an interesting type of institutional talk.

** Paolo Nino Valdez holds a PhD in linguistics from the Philippine Normal University and his dissertation which delves on culture and code switching was a finalist for the Christopher Brumfit Outstanding Dissertation Award in 2008. He is currently an Associate Professor of the Department of English and Applied Linguistics, De La Salle University, Manila, Philippines. In 2017, he was a visiting scholar in the English language and literature group of the National Institute of Education, Nanyang Technological University, Singapore. Aside from paper presentations in local and international conferences, his publications have appeared in Discourse, Context and Media, Asia Pacific Education Researcher, Journal of AsiaTEFL, and Malaysian Journal of Learning and Instruction. His research interests are in the areas of bilingual education, critical pedagogy and contemporary sociolinguistics. 


\section{REFERENCES}

Blommaert, J. 2010. The sociolinguistics of globalization. Cambridge: Cambridge University Press, https://doi.org/10.1017/CBO9780511845307.

City of Tacloban. 2015. http://www.tacloban.gov.ph (accessed 24 May 2017).

Floralde, R. and Valdez, P. N. 2017. Linguistic landscapes as resources in ELT: The case of a rural community in the Philippines. Journal of AsiaTefl 14 (4): 793-801, https://doi.org/10.18823/asiatefl.2017.14.4.15.793.

Gonzalez, A. 2004. The social dimensions of Philippine English. World Englishes 1: 7-16.

Gorter, D. 2006. Linguistic landscape: A new approach to multilingualism. London: Multilingual Matters.

Kress, G. and Van Leeweun, T. 2001. Multimodal discourse. London: Bloomsbury Academic.

Lamarre, P. 2014. Bilingual winks and bilingual wordplay in Montreal's linguistic landscape. International Journal of the Sociology of Language 228: 131-151, https://doi.org/10.1515/ijsl-2014-0008.

Lawrence, C. 2012. The Korean English linguistic landscape. World Englishes 31 (1): 70-92, https://doi.org/10.1111/j.1467-971X.2011.01741.x.

Lejano, R., Tan, J. M. and Wilson, A. M. 2016. A textual processing model of risk communication: Lessons from typhoon Haiyan. Weather, Climate and Society 8: 447-463, https://doi.org/10.1175/WCAS-D-16-0023.1.

Leung, G. and Wu, M. 2012. Linguistic landscape and heritage language literacy education: A case study of linguistic rescaling in Philadelphia Chinatown. Written Language and Literacy 15 (1):114-140, https://doi.org/10.1075/wll.15.1.06leu.

Martin, I. P. 2014. English language teaching in the Philippines. World Englishes 4: 472485, https://doi.org/10.1111/weng.12108.

Papen, U. 2012. Commercial discourses, gentrification and citizens' protest: The linguistic landscape of Prenzlauer Berg, Berlin. Journal of Sociolinguistics 16 (1): 56-80, https://doi.org/10.1111/j.1467-9841.2011.00518.x.

Pennycook, A. 2010. Language as a local practice. London: Routledge, https://doi. org/10.4324/9780203846223.

Phillipson, R. 1992. Linguistic imperialism. Oxford: Oxford University Press.

Renada, P. 2013. Yolanda/Haiyan damage now at P9.46B. Rappler, 13 November. http://www.rappler.com/move-ph/issues/disasters/typhoon-yolanda/4385820131116-yolanda-death-toll-ndrrmc-am-report (accessed 25 January 2017).

Scollon, R. and Scollon S. W. 2003. Discourses in place: Language in the material world. London: Routledge, https://doi.org/10.4324/9780203422724.

Seargeant, P. and Tagg, C. 2011. English on the internet and a 'post-varieties' approach to language. World Englishes 30 (4): 496-514, https://doi.org/10.1111/j.1467971X.2011.01730.x.

Shohamy, E. and Gorter, D. (eds.). 2009. Linguistic landscape: Expanding the scenery. New York: Routledge.

Spolsky, B. 2009. Prolegomena to a sociolinguistic theory of public signage. In Linguistic landscape: Expanding the scenery, eds. Shohamy, E. \& Gorter, D., 25-39. New York: Routledge. 
Stroud, C. and Mpendukana, S. 2009. Towards a material ethnography of linguistic landscape: Multilingualism, mobility and space in a South African township. Journal of Sociolinguistics 13 (3): 363-386, https://doi.org/10.1111/j.1467-9841. 2009.00410.x.

Tan, M. S. and Said, S. B. 2015. Linguistic landscape and exclusion: An examination of language representation in disaster signage in Japan. In Conflict, exclusion and dissent in the linguistic landscape, eds. Rubdy, R. and Said, S. B., 145-169. London: Palgrave MacMillan.

Tupas, T. R. F. 2007. Back to class: The ideological structure of the medium of instruction debate in the Philippines. In (Re)making society: The politics of language, discourse and identity in the Philippines, ed. Tupas, T. R. F., 61-84. Quezon City: University of the Philippines Press.

2008. Kalagayan, tawid-buhay and other uses of language in a marginal Philippine community: The place of language in literacy and social development. Journal of Bilingualism and Bilingual Education 11 (2): 226-245, https://doi. org/10.2167/beb495.0.

Valdez, P. N. 2011. English for colonization, neo-colonization, and globalization in the Philippines: Challenging marginalization in the profession. TESOL Journal Philippines 4 (1): 72-80. 